\title{
Manorama Singh: Blood Transfusion in Clinical Practice
}

\author{
Paras Medical Publisher, Hyderabad, 2011, ISBN:9788181913333
}

\author{
Gupta Usha
}

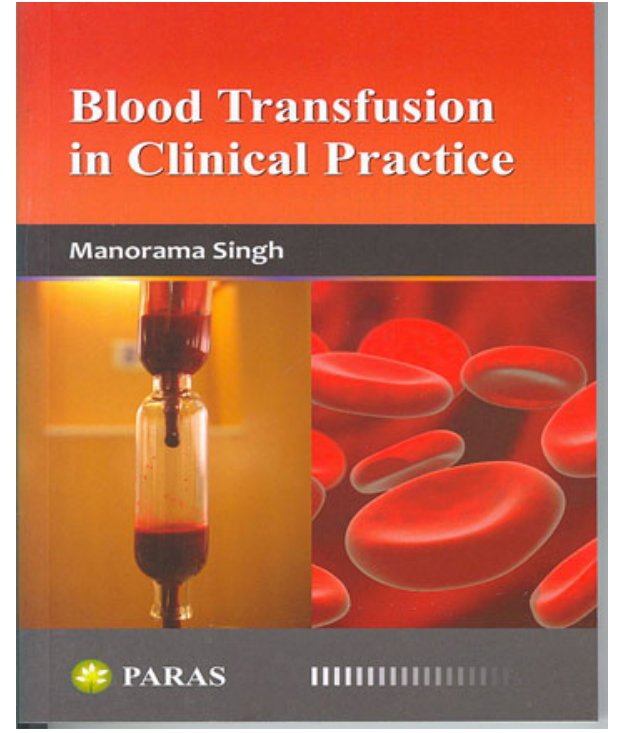

"Blood Transfusion in Clinical Practice," is authored by Dr. Manorama Singh, Ex-Professor and HOD Anaesthesia, Gandhi Medical College and Associated Hospitals, Bhopal, MP.

The author has done full justice to the title of the book by translating her vast clinical experience into written text.

The book begins with the background into the various milestones in history of emergence of blood transfusion.

Gupta U. ( $₫)$, Professor

Department of Obstetrics and Gynaecology, Lady Hardinge Medical College and Smt S.K. Hospital, New Delhi, India e-mail: ushaguptalhmc@gmail.com
The book gives fascinating account of discovery of blood groups, difficulties and hazards of blood transfusion and of recent performance of stem cell transplantation.

The physiology of composition and functions of blood has been made simple and easy to understand. Special chapters in the book deal with indications of blood, transfusion in special condition like anemia, cardio-pulmonary bypass, in pediatric population and in patients in the critical care unit. The book has dealt in detail with the pathophysiology of hemorrhage and coagulopathy along with their clinical consequences. Estimation of intra-operative blood loss, the concept of allowable blood loss and transfusion trigger, and the transfusion guidelines for blood and blood products have been described clearly. The chapter on massive blood transfusions cautions the clinicians on its hazards. The highlight of the book is the wealth of information on blood products, plasma substitutes, and blood substitutes, and description of the products available in the market, indications, contraindications, and complications of their use. The final chapters on oxygenation and blood bank give an insight into the rationale of blood transfusion, oxygen therapy, the working of blood bank, how blood and its products are stored and dangers of stored blood.

The addition of study questions and suggested reading at the end of every chapter is likely to benefit the students.

The book is bound to be useful for all clinicians from different specialities and paraclinical professional who may require giving blood to their patients at some stage of their lives. The practical tips given throughout the book makes it a must read book. 